\title{
Awareness about Personal Protective Equipments and Health Problems among Poultry Workers
}

\author{
S R Das', N Begum², C Biswas ${ }^{3}$, M N Hoq ${ }^{4}$, J Hossain ${ }^{5}$
}

${ }^{1}$ Dr. Shila Rani Das

Assistant Professor

Dept. of Community Medicine

Z. H Sikder Womens Medical College Dhaka

${ }^{2}$ Dr. Nasreen Begum

Assistant Professor

Dept. of Community Medicine

Northern International Medical College

${ }^{3}$ Dr. Chinmay Biswas

MD (Part-III)

Dept. of Skin \& VD, BSMMU

${ }^{4}$ Prof Md. Nazmul Hoq

Prof \& Head

Dept. of Physiology

Northern International Medical College

${ }^{5}$ Dr. Jahangir Hossain

Assistant Professor

Dept. of Psychiatry

Z H Sikder Womens Medical College

\section{Correspondence}

Dr. Shila Rani Das

Assistant Professor Dept. of

Community Medicine

Z. H Sikder Womens Medical College

Dhaka

\section{Abstract}

Background: Taking protective equipment is important for poultry workers as they are at risk of poultry hazard. Use of personal protective equipment (PPE) is essential for preventing \& controlling diseases experienced by poultry processing workers. ${ }^{1}$

Aims and Objectives: To assess the awareness about personal protective equipments and health problems among poultry workers.

Method and materials: Descriptive cross-sectional study was conducted under the guidance of the Department of Community Medicine, National Institute of Preventive and Social Medicine (NIPSOM), Dhaka, from March to June 2006 on 100 poultry workers who were selected purposively from six poultry farms from the area of Gazipur districts. Informed consent was obtained and structured questionnaire was used to collect data through face to face interview. Data was edited, processed and analyzed both manually and used of SPSS version 10.

Result: Mean age was $27.49 \%$ with SD \pm 9.84 years, highest age range $59 \%$ was 20.30 years. Regarding level of education \& economic status revealed that $43 \%$ were illiterate and $72 \%$ earned $2000-3000$ taka monthly. $20 \%$ had highest work experience of 6.8 years. $82 \%$ of the respondents thought that personal protection is necessary during working in poultry. $79 \%$ of the respondents knew the name of PPE. But only $42 \%$ use PPE and $58 \%$ of the respondents did not use it. Among the user $16 \%$ use PPE regularly and $26 \%$ use PPE irregularly. Result showed significant association between education and knowledge of diseases of transmission $(p<0.004)$. Observing health hazard $34.71 \%$ had respiratory problem $27.27 \%$ skin problem $23.14 \%$ eye problem. Significant association found between itching (skin problem) and use of PPE ( $p<0.004)$.

Conclusion : Literate person had more knowledge about disease transmissions. The respondents who used PPE suffered less from health problems. For the safety of poultry workers advocacy arrangements of training program and formulation of guideline and regulations are important points to be considered.

Key words : Awareness, Personal protective equipment (PPE), Health problem, Poultry worker.

Introduction : The poultry industry includes places such as hatcheries and farms where chicks are grown, feed mills, where grains are stored, selected and mixed for hatcheries and processing plants. Poultry industry plays important role in the agro-based economy of Bangladesh. It is one of the growing sectors and fitting example of how private initiative flourishes in an enabling environment vision and policy. The number of poultry farms has increased from 9750 in 1991 to 163193 in $2001 .^{2}$ Poultry workers include poultry growers and their employees, service technicians of poultry processing companies, caretakers, farm manager, layer barn workers and chick movers and chick moves at movers at egg production facilities. ${ }^{3}$ They are constantly exposed to agents causing health hazard in poultry industry. The expansion of poultry industry largely depends on the prevention and control of contagious diseases as well as on the use of personal protective measures by the workers working in poultry farms. Recent outbreak of highly pathogenic "Avian Influenza" in poultry has a new threat to poultry industry of Bangladesh. Appropriate disease prevention and management through bio-security is important of rearing poultry. ${ }^{4}$

Therefore, we must give special attention to poultry workers, because they spend the most of their time in the poultry premises and experience the greatest risk of exposure to a variety of contaminants including organic dusts, gases such as ammonia and microorganisms like viruses, bacteria, and fungi that can cause illness. Respiratory problem like allergic reactions, asthma, and hypersensitivities, pneumonitis, organic dust toxic syndrome (ODTS) can develop from prolonged exposure to air borne contaminants. ${ }^{5}$ Skin problems like dermatitis, rashes irritation, itching, ear problems like hearing loss and tinnitus, chemical exposures like irritation of the eyes are common hazards. Uses of PPE, maintenance of personal hygiene are important preventive measures against above health hazards. ${ }^{6}$

Method and Materials : Descriptive cross-sectional study was conducted under the guidance of the Department of Community Medicine, National Institute of Preventive and Social Medicine (NIPSOM), Dhaka, from March to June 2006 on 100 poultry workers who were selected purposively from six poultry farms from the area of Bagher bazar, Madhab Khola, Gargoria \& Mawna at Gazipur districts. The data were collected from the respondents through face-to-face interview by using a structured questionnaire. Informed consent was taken before interview. The obtained data were analyzed manually and also by using SPSS version 10 .

Result : A total 100 poultry workers were interviewed Mean age was $27.49 \%$ with (SD \pm 9.84 ) years highest age range $59 \%$ was $20-30$ years of age. Male respondent was more. Economic status of the workers 
were very low, $72 \%$ of the respondents earned 1000 to 2000 taka per month (mean 2172.50, SD \pm 709.38 ). Regarding poultry workers experience $5 \%$ had more than 3 years and $21 \%$ had $6-8$ years experience in working poultry farm. (Mean 1.72, SD \pm 0.965 ) (Table I).

Table 1 : Distribution of respondents by the their Socio-demographic Characteristic:

Age of respondents in years

$<20$

Frequency

Percentage (\%)

21-30

16

16.0

$31-40$

59

59.0

$>40$

17

17.0

8

8.0

Mean 27.49 S D \pm 9.840

Monthly income in taka

$\begin{array}{lcc}1000-2000 & 72 & 72 \\ 2000-3000 & 15 & 15.0 \\ 3000-4000 & 5 & 5.0 \\ >4000 & 8 & 8.0\end{array}$

Mean 2172.50 SD \pm 709.38

Length of services in years

$<3$

59

5.9

3-5

15

15.0

6-8

21

21.0

$>8$

$5 \quad 5.0$

\section{Mean 1.72 SD \pm 0.965}

Education level revealed $43 \%$ were illiterate, $37 \%$ primary, $14 \%$ secondary and about $3 \%$ were HSC passed. (Figure 1)

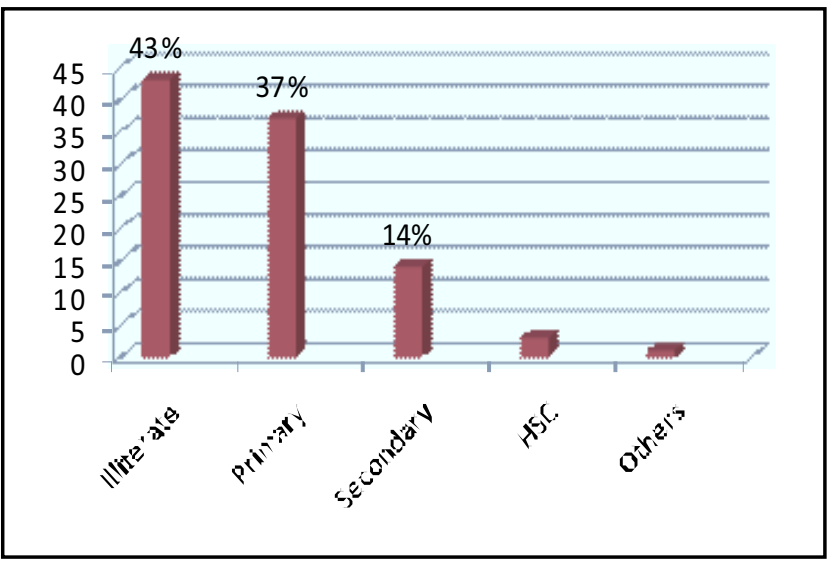

Figure 1: Distribution of respondents by their educational status

Among the respondents only $59 \%$ had knowledge about transmission of diseases $82 \%$ of the respondents had knowledge on personal protection is necessary during working in poultry and $79 \%$ knew the name of PPE (Table II)
Table II: Knowledge about diseases transmission, personal protection, and the name of PPE

Knowledge about

Disease transmission

Yes

No

Knowledge on

Personal protection

Yes

No

Know the name of PPE

Yes

No

$\begin{array}{cc}\text { Frequency } & \text { Percentage (\%) } \\ 59 & 59 \\ 41 & 41\end{array}$

82

82

$18 \quad 18$

$79 \quad 79$

$21 \quad 21$

Regarding PPE use $42 \%$ use PPE \& $58 \%$ did not use it. Among the PPE user $16 \%$, use PPE regularly and $26 \%$ use PPE irregularly (Table III).

Table III : Distribution of respondents by regular use of personal protective equipments.

\begin{tabular}{lcc} 
Use of PPE & Frequency & Percentage (\%) \\
Regular & 16 & 16 \\
Irregular & 26 & 26 \\
\hline Total user & 42 & 42 \\
Not user & 58 & 58 \\
\hline Total & 100 & 100
\end{tabular}

Among the respondents 42 (34.71\%) suffered from Respiratory problem followed by $33(27.27 \%)$ skin problem and eye problem 28 (23.14\%) (Figure 2)

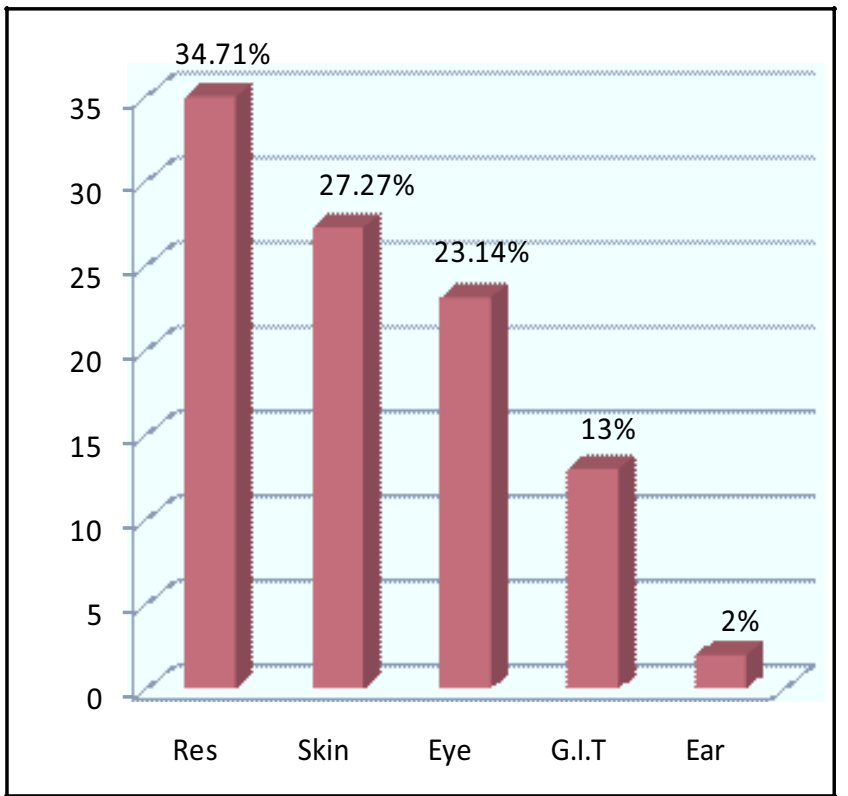

Figure 2: Different type of health problems among respondents

The study result also revealed that highly significant association was between education and knowledge of diseases transmission $(p=0.004)$. Also highly significant association between itching and use of PPE $(p=0.004)$ (Table IV). 
Table IV: Association between Education and Knowledge of disease transmission \& between itching and use PPE

\begin{tabular}{lll} 
Education & \multicolumn{3}{l}{ Knowledge of disease transmission } \\
& Yes $(\%)$ & No $(\%) \quad$ P value $<0.004$ \\
Literate & $43(52.4 \%)$ & $2(11.1 \%)$ \\
Illiterate & $16(88.9 \%)$ & $39(47.6 \%)$ \\
Total & $59(59.0 \%)$ & $41(41.0 \%)$
\end{tabular}

Itching (skin problem) Use of PPE ( \%)

$\begin{array}{lll} & \text { Yes }(\%) & \text { No }(\%) \quad \text { P Value }<0.004 \\ \text { Yes } & 14(42.4 \%) & 19(57.6) \\ \text { No } & 28(41.6 \%) & 39(58.2 \%) \\ \text { Total } & 42(42 \%) & 58(58 \%)\end{array}$

Discussion : The study was conducted among the 100 poultry workers among them majority 59\% were between 20-30 years of age (Mean age $27.49 \%, S D \pm 0.965)$ and $78 \%$ were male. Study done in Netherland reported a little higher age group and most workers were male. In our study Islam was major religious group (91\%). Most of them were illiterate (43\%) and next highest group 37\% were educated up to primary level. Majority of the workers (72\%) monthly income was low between 1000-2000/month. (Mean 2172.50, SD \pm 709.38 ). A few number $(5 \%)$ had job experience more than 8 years but highest number (21\%) had 6-8 years (Mean 1.72 , SD \pm 0.965$)$. Similar result found in Netherland study which reported that workers earn less and most of them had similar duration of work experience in this type of industry. ${ }^{6}$ During this study when the workers asked about transmission of diseases only $59 \%$ had knowledge about transmission of disease and $82 \%$ had knowledge on personal protection, they knew that personal protection is necessary during working in poultry. Most of the respondents $79 \%$ knew the name of PPE, but only $42 \%$ use PPE $58 \%$ of did not use it because authority did not supply them PPE. Among the users only $16 \%$ used regularly and $26 \%$ used irregularly.

On 14 April 2003 the Outbreak Management Team reported compliance with preventive measures was low. Among 124 poultry farmers in an infected farms, $22(17.7 \%)$ used mouth nose masks and $4(3 \%)$ used goggles while working. Only $8(6 \%)$ used masks consistently, and one person $(0.8 \%)$ always wore protective goggles. ${ }^{7}$ In this study, $42(34.71 \%)$ suffered from Respiratory problem followed by $33(27.27 \%)$ skin problem and eye problem 28(23.14). Version. $M$, at all reported that out of 4500 persons who had contacted with poultry in the infected areas, 453 reported health problems. ${ }^{8}$ Case studies conducted at six poultry processing plants by National Institute for Occupational Safety and Health (NIOSH), The Occupational Safety and Health Administration (OSHA), ${ }^{7}$ the U.S Department of Agriculture (USDA), ${ }^{9}$ and state health departments revealed that processors and inspector experienced acute eye and upper respiratory irritation associated with their work. The most frequently reported symptoms were burning, watery eyes, sneezing, stuffy, runny nose, and cough. Other symptoms included blurred vision, light sensitivity, sore throat, headache and nausea. ${ }^{10}$ There was significant association between Education and Knowledge of disease transmission $(p<0.004)$. Also significant association found between itching and use of PPE $(p<0.004)$.
Conclusion : This study showed that most of the workers had knowledge about personal protective equipments and literate persons had more knowledge about disease transmissions. Those respondents used PPE they suffered less health problems in comparison to illiterate person.

Recommendation : Awareness and training program about personal protective equipments should be arranged for the poultry workers, so that they should have update knowledge about disease related to their working environments. Government should formulate guidelines and regulations in relation to Occupational Safety \& Health Act (OSH act) for the poultry farms and their workers which should be followed strictly.

\section{References}

1. World Health Organization (2006) Public health interventions for prevention and control of avian influenza A manual for improving bio security in the food supply chain: focusing on live animal markets. New Delhi: Regional Office for South-East Asia

2. Proceedings of the $4^{\text {th }}$ international poultry show seminer. Dhaka, Bangladesh:Dhaka: World Poultry Science Association Bangladesh brance; 2005: 8-28. (Cited 2006 March 13)

3. Humphrices R. Michigan and response plan for highly pathogenic Avian Influenza in free-ranging wildlife [ online]. 2006 January 27 [Cited 2006 March13]: Available from URI:http://www. michigan.gov/dur.

4. Principal and practices of Bio-security in poultry farms. Mymensingh, Bangladesh. Mymensingh: Bangladesh society for veterinary education and research.2006. (Cited June 2006)

5. Frager LJ,Pollock K,Morton C. Occupational health and safety risk in the poultry industry. Sydney. Rural industry Reasearch and Development Corporation and Australian centre for Agriculture Health and safety. 2005 [cited 2006 March13] 218.

6. NC Stated University. Improving the Health and Safety of Poultry Facility Workers. [2005 March 13] [cited 2006 March 13] Avilable from: URL: http://www.bac.nesu.edu/programs/extension/farm safety/poultry.html

7. Latino Poultry Worker Injury Higher Than Reported to OSHA. Occupational Safety and Reporter. News.2005 Sep 29 [cited 2006 April 12]; 35 (38): page.854 Avilable from :

URL:http://subscript.bna.com/SAMPLES/osh.nsf/852563ef006c7aa

08525611300214487/ca88b7652f51bbd58525708a00731794

? OpenDocument

8. Verson. M, Kirychuk.S. Dorst, Jacobson. L. Human Health effect of dust exposure in animal confliments buildings. Journal of Agriculture Safety and Health.2000[cited 2006 April 12];6(4):URL:http:// asaefrymulti.com/ abstract.asp?aid $=1911 \& \mathrm{t}=2$

9. Farm land Animal Watch. 2006 March15 number 37 volume 5:p.1-7. URL: http;//www.farmedanimal.net/faw5-37.htm (Cited 2006 April 12)

10. Work place safety and health-safety in the Meat and Poultry Industry, while Improving Could Be Further Strengthened(GAO-05-96). Report to the Ranking Minority Member, Committee on Health, Education, Labor, and Persions, U.S. Senate.2005 January [2006 March 13];p.1-75. 